\title{
Impacts of Groundwater Flow on Evolution of a Thermokarst Lake in the Permafrost Region on the Qinghai-Tibet Plateau
}

\author{
Wei Wang ${ }^{1}$, Jinlong $\mathrm{Li}^{1}$, Xianmin $\mathrm{Ke}^{1}$, Kai Chen ${ }^{1}$, Zeyong $\mathrm{Gao}^{2}$, and Fujun $\mathrm{Niu}^{2}$ \\ ${ }^{1}$ Chang'an University \\ ${ }^{2}$ Cold and Arid Regions Environmental and Engineering Research Institute
}

March 2, 2021

\begin{abstract}
Thermokarst lakes and permafrost degradation in the Qinghai-Tibet Plateau (QTP) resulting from global warming have been considerably affected the local hydrological and ecological process in recent decades. Simulation with coupled moisture-heat models that follows talik formation in the Beiluhe Basin (BLB) in the hinterland of permafrost regions on the QTP provides insight into the interaction between groundwater flow and freezing-thawing process. A total of 30 modified SUTRA schemes have been established to examine the effect of hydrodynamic forces, permeability and climate. The simulated results show that the hydrodynamic conditions impact the permafrost degradation surrounding the lake, thereby further affecting groundwater flow and late-stage freezing-thawing process. The thickness of the active layer varies with time and location under different permeability conditions, which significantly influences the occurrence of a breakthrough of the lake bottom. Warmer climate accelerates thawing and decreases the required time of formation of the breakthrough zone. Overall, these results indicate that explicit consideration of hydrologic process is critical to improve the understanding of environmental and ecological changes in cold regions.
\end{abstract}

\section{Hosted file}

Manuscript.pdf available at https://authorea.com/users/399015/articles/511589-impacts-ofgroundwater-flow-on-evolution-of-a-thermokarst-lake-in-the-permafrost-region-on-theqinghai-tibet-plateau 